\title{
O ESTÁGIO SUPERVISIONADO E A FORMAÇÃO DOCENTE: PERCEPÇÕES A PARTIR DE RELATOS DE HISTÓRIAS DE VIDA
}

\author{
THE SUPERVISED PRACTICE AND THE EDUCATIONAL FORMATION: PERCEPTIONS FROM \\ REPORTS OF LIFE STORIES
}

Josilda da Conceição Novacoski da Silva*

Leonides Ferreira da Silva**

*Mestranda do PPG em Geografia/UNICENTRO/Guarapuava, josildacnsilva@hotmail.com.

** Geógrafo/ Mestre em Geografia/UNICENTRO/Guarapuava, leonides-silva@hotmail.com.

Recebido em 17/08/2018. Aceito para publicação em 25/08/2018.

Versão online publicada em 03/09/2018 (http://seer.ufrgs.br/paraonde)

\begin{abstract}
Resumo:
O presente trabalho é resultado de uma pesquisa realizada com acadêmicos do 4o ano de Licenciatura em Geografia e tem como principal objetivo compreender a importância do Estágio Supervisionado na formação dos futuros professores. A pesquisa buscou compreender o perfil desses sujeitos, perceber os desafios e as superações encontradas no decorrer do Estágio Supervisionado, bem como as expectativas com relação ao futuro profissional. A pesquisa foi realizada com 28 acadêmicos e a partir dos dados obtidos pelos questionários, foram selecionados 7 acadêmicos, os quais produziram os relatos sobre suas histórias de vida com vistas a evidenciar a importância do Estágio Supervisionado na formação inicial docente. A partir da experiência com esses sujeitos, a pesquisa terá continuidade por meio do projeto de mestrado, visando compreender o papel desse componente curricular para os egressos do Curso de Licenciatura em Geografia.
\end{abstract}

Palavras-chave: Formação Docente; histórias de vida; estágio supervisionado.

\begin{abstract}
:
The present work is the result of a research carried out with 4th year undergraduate students in Geography and its main objective is the importance of Supervised Practice in the training of future teachers. The research sought to visualize the profile of the subjects, perceive the challenges and how overcomes found without results of the Supervised Practice, as well as a relation with the professional future. The research was carried out with 28 academics and from the data obtained by the questionnaires, 7 academics were selected, which produced the reports on their life histories with perspectives to evidence the importance of the Supervised Practice in the initial teacher training. From the experience with the subjects, a research with continuity through the master project, aiming at the role of the curricular component for the graduates of the Degree course in Geography.
\end{abstract}

Key-words: Educational Formation; Life Histories; Supervised Practice.

\section{Introdução}

0 presente trabalho visa relatar a experiência realizada com acadêmicos do $4^{\circ}$ Ano de Licenciatura em Geografia da Universidade Estadual do Centro-Oeste - UNICENTRO, Guarapuava-PR, e tem como principal objetivo compreender a importância do Estágio Supervisionado na formação dos futuros professores. Essa é uma parte da pesquisa em andamento no âmbito do programa de pós-graduação em Geografia, nível de mestrado, na mesma universidade.

O Estágio Supervisionado, na formação inicial, configura o primeiro contato do acadêmico com o futuro ambiente de trabalho, a sala de aula e, conforme Kulcsar (2012, p. 58) é "[...] um instrumento fundamental no processo de formação do professor. Poderá auxiliar o aluno a compreender e enfrentar 
o mundo do trabalho e contribuir para a formação de sua consciência política e social, unindo a teoria à prática."

No entanto, há pesquisas que demonstram uma grande fragilidade na execução desse componente curricular nas universidades do Brasil, uma vez que, segundo Gatti (2014) em algumas Instituições de Ensino Superior (IES) não se cumpre a legislação e há uma dissonância entre o que está previsto para a realização do estágio e o que é efetivamente realizado. Exceção àquelas IES que priorizam a articulação entre elas e as escolas fato que resulta numa formação de boa qualidade.

Porém, embora haja essas contradições é possível afirmar que por meio do Estágio Supervisionado é possível obter uma experiência inicial que inspire o futuro professor a ser mediador dos conhecimentos, que busque a auto avaliação e autorreflexão para que suas intervenções sejam satisfatórias no ambiente escolar. Contudo, a formação iniciada na Universidade é apenas o "pontapé" inicial, pois "sabemos que a universidade não é capaz de oferecer ao mercado de trabalho um professor pronto, porque o professor é o sujeito de sua história, protagonista de seu tempo e de seu trabalho" (CAMPOS, 2012, p. 14).

No intuito de compreender esse processo, buscou-se entender, por meio de narrativas das histórias de vida desses sujeitos, no caso, acadêmicos do curso de licenciatura em Geografia, da UNICENTRO, o papel desse componente curricular em sua formação, com vistas a delinear meios mais eficazes à construção da formação docente.

Inicialmente, participaram 28 acadêmicos do quarto ano, por meio de uma pesquisa exploratória, com qual se obteve uma caracterização do perfil dos formandos em licenciatura, no ano de 2016 e, dentre esses, foram selecionados 07 acadêmicos que efetuaram as narrativas das suas histórias de vida. Os critérios básicos de seleção foram à faixa etária, gênero, estado civil e a participação ou não em atividades extracurriculares, buscou-se uma heterogeneidade tal qual encontra no coletivo de formandos. Cada história de vida proporcionou ao trabalho um arcabouço de dados que permitiu delinear um panorama mais amplo da formação dos sujeitos e colaborou para evidenciar o papel do Estágio Supervisionado na formação inicial docente.

Desta forma, a presente pesquisa procurou trazer à tona a discussão sobre a formação inicial de professores que tem como fundamento essencial os cursos de licenciatura, porém, não se limita a esse pequeno percurso que o sujeito percorre, mas sim a sua trajetória, implicando na formação ao longo de toda a sua história de vida.

\section{Desenvolvimento}

0 tema ora estudado tem relevância significativa, pois busca uma forma de repensar a formação inicial docente tendo como base a compreensão de que o sujeito é um ser em constante formação, portanto, os saberes vão se consolidando a partir de sua história de vida: do início de sua vida escolar, na sua trajetória acadêmica e, posteriormente, na sua atuação profissional. Cabe aqui, portanto, procurar compreender o que levou esses sujeitos, em se tratando dos acadêmicos que estão cursando o $4{ }^{\circ}$ ano do curso de licenciatura, a decidir pela docência e, principalmente, o que os motiva a permanecer, a partir de sua experiência no curso, na carreira docente.

As narrativas das histórias de vida possibilitaram perceber quem são os sujeitos que estão concluindo a graduação e que poderão estar atuando nas salas de aula como professores de Geografia. Conforme Burnier et al (2007, p. 344) "As narrativas ou entrevistas de história de vida oferecem o marco teórico-metodológico adotado ao investigarmos os percursos pessoais e profissionais de docentes da educação profissional". E, neste sentido, Santos (2012, p. 25) considera que "é possível concluir que as narrativas não servem apenas para relatar o que está posto, mas também para possibilitar novas alternativas, confirmando a sua extraordinária importância nos estudos e pesquisas educacionais". 


\title{
3. Resultados e discussão
}

\subsection{A escolha pela geografia}

Ensinar Geografia é desafiador e traz consigo grandes implicações capazes de fazer com que muitos alunos se apaixonem pela disciplina ou até mesmo os traumatizem e não gostem dela. Por isso, o papel do professor é fundamental para que se realize uma educação que tenha significado no cotidiano desses alunos. Callai (2013) afirma que "a educação geográfica é a possibilidade de tornar significativo o ensino de um componente curricular sempre presente na educação básica". Portanto, deve superar a ideologia de apenas passar o conteúdo, e ensinar pautado em discussões que trazem questões do mundo da vida, para além do que o currículo propõe.

Neste sentido, na pesquisa, constatou-se a importância que o professor de Geografia tem na vida dos alunos. Esses sujeitos trazem consigo histórias de vida distintas, afinal, cada ser humano é único e tem suas características individuais, porém, percebe-se que alguns casos se assemelham, como a motivação pela docência, vinculadas a influência do professor na educação básica e a aproximação dos familiares que atuam ou atuaram como professores:

[...]motivada pela minha mãe, que é professora, e pelos bons professores que tive no ensino médio, optei pela geografia, que era a minha matéria preferida. É certo que nessa época eu ainda tinha muitas dúvidas se foi a escolha certa, mas o fato foi que passei no vestibular e decidi tentar. F1

Os professores da educação básica, muitas vezes, marcam a trajetória de vida dos sujeitos, se tornando referências como imitação de modelos:

A minha escolha pela Geografia vem de muitos anos atrás, lá durante os tempos de escola, onde essa disciplina era a que eu considerava mais interessante, sendo que meu professor de forma indireta também me incentivou. M2

\begin{abstract}
Minha escolha pela licenciatura, veio principalmente pela admiração dos meus professores e, no ensino médio, por influência também da minha irmã mais velha que cursava licenciatura e hoje é professora. A opção pela Geografia se deu, eu acredito que quase $100 \%$, por incentivo dos professores, mas principalmente de um professor do ensino fundamental. 0 melhor professor que já tive na vida, e que influenciou vários colegas que hoje estão no curso de Geografia. M3
\end{abstract}

Sempre fui influenciada pela geografia, tenho uma conhecida que fez geografia e eu sempre a admirava por isso e também tenho um tio que fez geografia e acredito que essas duas pessoas me inspiraram desde pequena, e ambos fizeram graduação de geografia na licenciatura. F2

Os bons professores tornam-se não só inspirações quanto à escolha da profissão, quanto a modelos a serem seguidos. Assim como os "maus" professores são lembrados negativamente e, juntos, contribuem para a construção de uma representação e expectativa de como atuar como professor. Sobre isso, Tardif e Raimond (2000, p. 215) concluem que "o saber profissional está, de um certo modo, na confluência entre várias fontes de saberes provenientes da história de vida individual, da sociedade, da instituição escolar, dos outros atores educativos, dos lugares de formação etc."

\subsection{Aspectos na formação durante a graduação}

As narrativas permitem uma análise bastante significativa com relação à formação do sujeito, 
enquanto acadêmico, na Universidade. Nos relatos, foi possível constatar que a busca pelo conhecimento vai além da participação das disciplinas curriculares em sala de aula. Observa-se que as atividades extracurriculares foram fundamentais na formação:

De fato, o curso foi muito bom para mim, em muitos sentidos[...]. Sempre tive boa relação com os meus professores e tentei, no que estava dentro das minhas possibilidades, aproveitar ao máximo a universidade. Nesse sentido, comecei a fazer Iniciação Cientifica, que foi de suma importância para o meu crescimento acadêmico. Com ela, aprendi a escrever melhor, a ter o hábito da leitura e da investigação. F1

A minha avaliação sobre meu processo de formação, o qual vejo hoje como ter valido a pena, talvez seja pelo fato de ter perdido meu emprego [...]. Esse momento da minha vida me incentivou ou até mesmo forçou a entrar no programa PIBID, a princípio interessado na bolsa de 400 reais, mas também me fez dedicar mais a graduação por ter mais tempo e ser um programa voltado à docência. M2

Desde o primeiro ano, quando iniciei a minha graduação eu fiz IC, foram 3 anos adquiri bastante conhecimento, principalmente na área de solos, onde eu desenvolvia meus projetos. Agora no $4^{\circ}$ ano eu estou participando do PIBID, gosto muito, pois os projetos desenvolvidos nas escolas são importantes para o aluno e para eu aperfeiçoar meu conhecimento e habilidades em sala de aula. F4

[...]surgiu a oportunidade de realizar Iniciação Científica, algo que foi muito bom para mim. Aprendi a escrever melhor, desbravei e me apaixonei pelo meu tema, criei laços de amizades com os colegas de laboratórios, realizei leituras e debates e participei de eventos que somente a graduação não conseguiria me proporcionar. A iniciação científica foi uma arma, que me pressionava, abria caminhos e que sem dúvidas me fez crescer. M3

Os programas de iniciação científica e a docência são reconhecidos pelos acadêmicos como fundamentais para sua formação e também para a construção de sua identidade profissional, especialmente, o programa Institucional de Iniciação à docência (PIBID) que proporciona ao licenciando uma oportunidade de interação entre a teoria e a prática, e extrapola os conhecimentos adquiridos nas disciplinas curriculares, e assim, proporcionam um grande aprendizado.

Calderano (2013, p. 50) aponta aspectos positivos do PIBID, "tanto do ponto de vista do estudante universitário, em processo de formação, quanto do professor da universidade orientador do programa", fator esse que traz benefícios consideráveis para a formação, como relata o acadêmico:

Em 2014 ingressei no PIBID (Programa Institucional de Bolsa de Iniciação à Docência), na época foi uma porta que se abriu para mim na graduação, eu precisava de dinheiro e como o Programa oferecia bolsa não pensei duas vezes, me inscrevi e fui selecionada.[...] Pude conhecer como é realmente uma sala de aula e o convívio em uma escola graças ao Programa, sem contar o quanto melhorou minha vida quanto acadêmica, em apresentações em sala de aula, e até mesmo nas práticas de estágio, pois a noção de sala de aula, de aluno e de conteúdo o PIBID já havia proporcionado. F3

Observa-se que os acadêmicos enfatizam o papel do auxilio financeiro como um dos primeiros motivos a buscarem os programas extracurriculares, contudo ao participarem das ações verificam que além da remuneração, a participação em projetos desta natureza, contribuem significativamente para a sua formação. Acadêmicos que não tiveram essa experiência recitem de não ter a mesma oportunidade:

[...]acredito que eu poderia ter aproveitado mais os programas oferecidos pela Universidade, como a Iniciação Cientifica e o PIBID, mas fui deixando e acabei desistindo. Eu acredito que poderia ter participado mais dos eventos e dos trabalhos desenvolvidos[...] F2.

No geral a graduação propiciou muito aprendizado, viagens (locais que nunca imaginava ter 
chance de conhecer), sinto que poderia ter "vivido" mais a Universidade, ter feito uma iniciação científica, porém não me arrependo de nada que passei aqui, espero ficar mais alguns anos aqui, outra graduação ou mestrado quem sabe. M1

0 arrependimento por não se envolver nas atividades extracurriculares, sobretudo, quando têm a oportunidade de participação e optam por não se envolverem está no fato desses acadêmicos observarem como os programas fazem diferença na formação dos colegas de turma, e atribuem a eles o melhor desempenho na formação. Verifica-se que a experiência extracurricular evidencia um crescimento e envolvimento maior com o curso e cria uma identidade profissional, fator fundamental na docência.

Porém, chama atenção que independente dos programas extracurriculares os acadêmicos reconhecem que o ambiente do curso, com atividades que envolvem viagens e pesquisas curriculares são importantes para sua formação, para além das expectativas iniciais. Há uma ampliação de sua visão de mundo e uma descoberta da função social da licenciatura.

\title{
3.3 A experiência do estágio supervisionado
}

A disciplina de Estágio Supervisionado tem se consolidado como um marco fundamental na formação inicial de professores. Neste sentido, Saiki e Godoi $(2013$, p.27) salientam que é este momento que colocamos as teorias em prática considerando que "[...] essa construção relacional é infinita, e quanto mais nos debruçamos sobre a teoria, mais nossa prática pode ser melhorada; quanto mais analisarmos as práticas, mais fundamentos podemos identificar", e assim fica evidente a necessidade de busca pelo conhecimento. Desta forma, por meio das narrativas, os acadêmicos evidenciaram essa importância do estágio em sua formação:

\begin{abstract}
Por falar em estágio, estes foram enriquecedores no sentido de que me ajudaram imensamente a aprimorar minha prática profissional. Com eles percebi muitas das dificuldades em lecionar e aprendi algumas "artimanhas" para desviar delas [...] Até então, tudo que era teoria virou prática. Eu fiquei cara a cara com o que iria enfrentar pela frente, nas salas de aula. Percebi que não seria tarefa fácil seguir em frente, mas toda profissão tem suas dificuldades. F1

A minha experiência no estágio foi gratificante, principalmente no quarto ano e por ser em dupla, onde isso passa uma segurança maior e também por ter mais experiência devido ao estágio anterior, além do fato dos alunos serem do ensino médio, a qual considero ser mais o meu perfil. Essa disciplina torna-se importante por dar um pouco da noção de como é a realidade do professor. M2
\end{abstract}

Os estágios supervisionados constituem espaços privilegiados em que o licenciando tem a oportunidade de conhecer o ambiente que será seu campo de trabalho, e assim, ocorre um amadurecimento muito satisfatório quanto às realidades escolares e às atividades docentes (GATTI, 2013-2014). Os relatos apontam esse amadurecimento:

O estágio supervisionado foi parte indispensável na formação, na verdade é parte fundamental na formação de qualquer profissional. Minhas experiências no estágio foram ora muito produtivas e ora bagunçadas e esquisitas. Quando fiz o estágio sozinho tive foi mais facilidade, me sentia mais condutor do conteúdo, mais professor, e também me dedicava mais, pois na hora sabia que ninguém estaria lá para me salvar. M3

A disciplina de estágio é uma das mais importantes no curso de licenciatura, e com certeza foi importante para eu compreender a profissão, pois uma coisa é você ser aluno, outra é você trocar de lugar e se colocar no lugar do professor e seguir dando aulas, transmitindo os conteúdos, encarando as dificuldades e conhecendo cada aluno, sua realidade e seu 
comportamento. F2

O estágio foi uma das partes mais importantes da graduação, foi com ele que pude articular a teoria com a prática, conheci diferentes alunos e diferentes professores, também conheci escolas diferentes onde vivenciei realidades diferentes. 0 estágio foi fundamental para que eu pudesse compreender meu futuro local de trabalho e principalmente minha profissão, pois me proporcionou experiências tão importantes que apenas na teoria eu não seria capaz de obtêlas, [...] F3

Minha experiência no estágio foi tranquila, só no início que tive um pouco de dificuldade em dominar as turmas agitadas, mas depois com o passar do tempo fui adquirindo mais experiência, a prática foi importante para eu compreender minha profissão, pois foi através do estágio que tive o contato com a realidade do meio escolar como (indisciplina, precariedade da escola, desigualdade social e etc.) e também as coisas boas como (alunos dedicados, escolas bem cuidadas pelos profissionais e alunos, etc.). F4

Todos os acadêmicos pesquisados identificam no estágio a relação direta com exercício profissional, os desafios impostos a prática docente e a construção dessa identidade. Os relatos confirmam que o estudo sobre a formação inicial de professores traz consigo o grande desafio de indagar e tentar decifrar quais são os caminhos a percorrer para que os futuros professores possam ser protagonistas de uma realidade inovadora capaz de instigar em seus alunos o desejo de aprender, sem que isso seja algo frustrante e cansativo. Assim, a busca pela compreensão da formação docente com base nas histórias de vida, permitem compreender o sujeito como um ser em construção, que está em constante processo de formação. Neste sentido, Veiga e Viana (2012, p.14) argumentam que:

\begin{abstract}
Nossa condição humana nos caracteriza como seres inacabados, com capacidade de criar e, consequentemente, de sempre buscar algo. É a inquietude, a curiosidade, a insatisfação que alimentam e estimulam o homem a novas conquistas no cotidiano, como temos constatado ao longo da história da humanidade. Essa história é escrita e modificada a cada segundo por determinações sociais, fruto do progresso da ciência e da interferência do homem no rumo da nossa sociedade.
\end{abstract}

Portanto, fica evidente que a formação do sujeito se dá no cotidiano, com as influências positivas e negativas de quem o acompanha. Cada acontecimento traz consigo um aprendizado e, neste sentido, a autora acrescenta que "a formação é contínua, vinculada à história de vida dos sujeitos em permanente processo de formação, que proporciona a preparação para a vida pessoal e profissional". (VEIGA e VIANA, 2012, p. 20)

\title{
4. Considerações Finais
}

A formação docente se dá a partir de experiências que o sujeito adquire ao longo de sua trajetória de vida. Desde suas primeiras vivências no ambiente escolar, passando pela graduação até sua carreira profissional. A cada dia novas experiências acrescentam um aporte em sua formação.

Ao investigar as histórias de vida dos sujeitos em formação, foi possível observar alguns aspectos fundamentais que permeiam esse processo e conduziram a percepções tais quais estão relacionadas a essas narrativas.

No que diz respeito a avaliação da graduação na formação é importante ressaltar que o aproveitamento das oportunidades em atividades extracurriculares oferecidas pela Universidade é de grande valia para a formação dos sujeitos, proporcionando maior desenvolvimento e crescimento na formação da identidade profissional, assim, a importância do Estágio Supervisionado também é expressa nos relatos, trazendo aos acadêmicos uma visão de como é o cotidiano escolar. 
As últimas normativas voltadas às reformulações curriculares dos cursos de formação de professores, Diretrizes Curriculares para Formação de Professores, 2002 e 2015, tem em comum a ampliação da carga horário do estágio supervisionado e a defesa da maior organicidade desse componente curricular no âmbito dos cursos de licenciatura. Embora ainda haja muito a avançar, essas mudanças têm significativo papel na construção da identidade profissional e na formação dos professores. Outro fator importante diz respeito ao Plano Nacional de Educação que reconhece que a valorização do professor, por meio da melhoria salarial e das condições de trabalho, é fundamental para garantir que mais jovens interessem-se pela licenciatura e, em relação aos formados, que estes optem pelo exercício da profissão. Essa é uma luta essencial que não pode ser dissociada da melhoria na formação inicial do professor.

\section{Referências}

BURNIER, S. et al. Histórias de vida de professores: o caso da educação profissional. Revista Brasileira de Educação, v. 12, n. 35, 2007.

CALDERANO, M. A. Docência compartilhada entre universidade e escola: formação inicial e continuada através do estágio curricular. São Paulo: FCC/CNPq 2013.

CALLAI, H. C. A formação do profissional de geografia: o professor. Ijui- RS: Unijui. 2013.

CAMPOS, M.de C. A formação do professor de geografia: a difícil construção do saber/fazer docente. Geosaberes, Fortaleza, v. 3, n. 6, p. 3-15, jul./ dez. Disponível em:<http://www.geosaberes.ufc.br/seer/index.php/geosaberes/article/view/124>Acesso em: $02 \mathrm{de}$ Setembro de 2016.

GATTI, B.A. Formação inicial de professores para a escola básica: As licenciaturas. Revista USP, São Paulo, n. 100, p. 33-46, dez/jan/fev. 2013-2014

GATTI, B.A. Formação inicial de professores para a escola básica: pesquisas e políticas educacionais. Est. Aval. Educ., São Paulo, v. 25, n. 57, p. 24-54, jan./abr. 2014

KULCSAR, R. O estágio supervisionado como atividade integradora. In: PICONEZ, Stela C. Bertholo (Coord.). A prática de ensino e o estágio supervisionado. Campinas-SP: Papirus, 2012

SAIKI, K.; GODOI, F.B. A prática de ensino e o Estágio supervisionado. In: PASSINI E. Y. Prática de Ensino de geografia e estágio Supervisionado. São Paulo: Contexto, 2013

SANTOS, M. F. P. dos. O estágio enquanto espaço de pesquisa: caminhos percorridos na formação docente em Geografia. Porto Alegre, 2012. 130 fl.Tese (doutorado) - Instituto de Geociências da Universidade Federal do Rio Grande do Sul (UFRGS), 2012.

TARDIF, M.; RAYMOND, D. Saberes, tempo e aprendizagem do trabalho no magistério. Educação e Sociedade. Campinas, ano 21, no 73. p.209-244, dez./2000

VEIGA, I. P. A.; VIANA, C.M.Q.Q. Formação de professores: um campo de possibilidades inovadoras. In: VEIGA, I. P. A.; SILVA, E. F. (Orgs.). A escola mudou. Que mude a formação de professores! 3.ed. Campinas-SP: Papirus, 2012 